\title{
Mis libros, el terremoto y lo que vino después
}

\author{
My books, the earthquake and after that
}

$\mathrm{D}$ esde la terraza de mi casa puedo ver el campanil del campus de la Universidad de Concepción. Durante varios días el reloj fijó la hora aciaga del terremoto que tanto nos ha marcado; sin embargo, para muchos lo que vino después fue peor.

Dentro de mi casa, aparte de la caída de fotos, algunos electrodomésticos, la desconexión y reubicación de una gran estufa a pellet -por la fuerza de la naturaleza- y destrucción de paredes en el zócalo, lo que más había en el suelo eran libros. Reiniciamos como familia la tarea de reordenarlos, así el primero fue "La Montaña Mágica" de Thomas Mann: primero recordé ese magnífico diagnóstico diferencial planteado por el Dr. Behrens al ver que Hans Castorp no mejoraba en el sanatorio, "usted tiene streptos", considerando como diagnóstico alternativo a la tuberculosis una endocarditis infecciosa de evolución subaguda; pero ¿que habrían discurrido Hans Castorp y su mentor latino Settembrini sobre los saqueos sistemáticos y organizados en amplias zonas de la región? Después tomé "La Muerte en Venecia" y "las Tablas de la Ley"; donde se relataba el amor prohibido de Gustavo von Ashenbach y su muerte por cólera y en el segundo la advertencia de Moisés de no poner los ojos en los bienes de otros para codiciarlos; luego "Guerra y Paz" de Tolstoi, cómo me hubiera gustado ver el infinito azul que pudo ver con emoción el príncipe Bolkonski cuando recuperó el conocimiento después de haber sido herido gravemente en batalla; la noche del terremoto y a pesar de las estrellas, hubo un incendio en la escuela de Ingienería Química, réplicas, explosiones y sirenas; así se me hacía recurrente futilidad de la vida, algo tan propio de Tolstoi y la posibilidad de redención narrada en Resurrección. Muchos otros libros fueron reordenados con cariño, de hecho, estaba la saga del comisario Salvo Montalbano y su adicción a la buena mesa, la lectura y el mar; especialmente importante también fue tomar la "Suite Francesa" de Irene Némirovsky, que en un relato coral muestra la descomposición de la sociedad francesa ante el incontenible avance alemán durante la segunda guerra mundial, ¿algo así nos pasó a nosotros, eso explica que no sólo el lumpen robó? Tal vez todo fue simplemente "un día de cólera", como la novela de Arturo Pérez-Reverte, sobre el levantamiento español en 1808 contra la ocupación francesa, gran novela por lo demás, pero superada en ritmo por "Cabo Trafalgar" del mismo autor. Siguen otros, muchos otros libros, a lo mejor todo esto se debe a nuestro mestizaje, condición que planteó con énfasis Leopoldo Castedo en "Contramemorias de un Transterrado"; aunque por otra parte, el apego a las instituciones no sea tampoco una constante española -tuve en la mano también "La Guerra Civil Española" de Antony Beevor y para redundar más con el planteamiento "Anatomía de un Instante" de Javier Cercas, donde se describe la conspiración y fallido golpe contra la incipiente democracia española después de décadas de dictadura franquista-. Incluso encontré parangones entre características tan nuestras y que se acrecentaron con el cataclismo como el gran número de perros vagos, con el "Estambul: Ciudad y Recuerdos" de Orhan Pamuk, donde este gran escritor describe como propios de la antigua Bizancio, los perros vagos, los palacios de madera que se quemaban con facilidad y el aire nostálgico de la ciudad; más aún, el autor relata su infancia en una gran edificio familiar, que tenía el nombre de la familia, ¿en

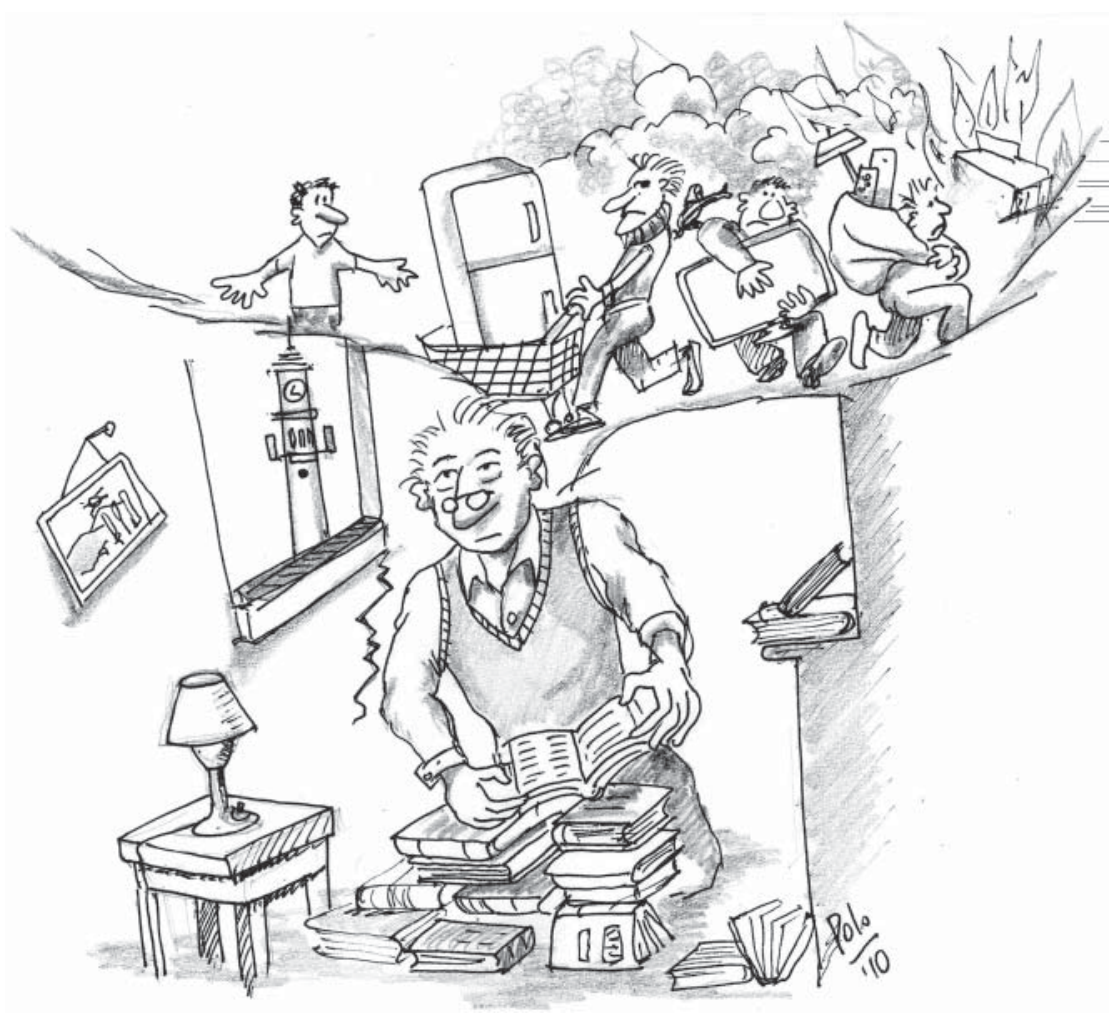


una región tan sísmica como Turquía hubiera resistido el edificio Pamuk un terremoto 8,8 en la escala Richter? Por otra parte, nos repetimos que la tragedia pudo ser peor, lo que queda meridianamente claro con la saga del ya nombrado escritor británico A. Beevor que tiene como punto culminante "Berlín, la Caída". También con Günter Grass en a "Paso de Cangrejo", donde relata en forma elíptica el hundimiento del paquebote alemán Wilhelm Gustloff, con miles de refugiados a bordo o su nítido recuerdo de la pérdida de la niñez con el bombardeo de Danzig por el Schleswig-Holstein, en "Pelando la Cebolla".

Mirando los libros, pienso en la estudiante que le arrojó agua a la ministra de Educación, en aquéllos que recientemente no sólo se contentaron con terminar de destruir un liceo en Talcahuano, sino que también rayaron las paredes y defecaron en las salas, en la diferencia con América del Norte donde una de las palabras que mas se escucha es "excuse me", mientras que acá imprecaciones referidas al huevo y a la madre, en los bocinazos inmediatos y agresivos, en el creciente desprecio a la reglamentación del tránsito y sobre todo en la creciente convicción -animada muchas veces desde las altas esferas políticas- que sólo tenemos derechos y pocos o casi nulos deberes. Si a este contexto le añadimos nuestra mediocridad intelectual refrendada en datos gruesos entregados por la prensa, como que la mitad de nosotros no entiende lo que lee o que un obrero alemán tiene una capacidad de comprensión de lectura comparable a un ejecutivo chileno, pasando por la pésima formación de buena parte de nuestros profesores completamos un cuadro que permite, aunque sea mínimamente, entender algo de lo que nos pasó. El terremoto demostró en forma tajante que tanto computador, internet, twitter, celulares con todos los adelantos tecnológicos imaginables no sirvieron y que una radio a pila que nos permitió escuchar Bío-Bío, la Radio, fue una gran compañera.

Dietrich Schwanitz en el prólogo de "Libros todo lo que hay que leer" de su compatriota Christiane Zschirnt nos recuerda que los nazis quemaron libros para preparar a los alemanes para la guerra, en cambio los estadounidenses antes de enviar a sus tropas a la guerra estimularon la lectura con los great book courses. Mi certeza es que una sociedad que lee y que lee, puede hacer algo más gruesa esa delgada corteza que llamamos cultura.

Sergio Mella $M$. Hospital Clínico Regional de Concepción Facultad de Medicina, Universidad de Concepción 